\title{
EFFECT OF LOCATION, GENOTYPE AND THEIR INTERACTIONS FOR ANTHOCYANINS AND ANTIOXIDANT ACTIVITIES OF PURPLE WAXY CORN COBS
}

\author{
Suchittra KHAMPAS ${ }^{1}$, Kamol LERTRAT ${ }^{1,3}$, Khomsorn LOMTHAISONG ${ }^{2}$, Sakunkan SIMLA ${ }^{4}$, \\ Bhalang SURIHARN ${ }^{1,3^{*}}$ \\ ${ }^{I}$ Khon Kaen University, Faculty of Agriculture, Department of Plant Science and Agricultural Resources, \\ Khon Kaen, THAILAND \\ ${ }^{2}$ Khon Kaen University, Faculty of Science, Department of Biochemistry, Khon Kaen, THAILAND \\ ${ }^{3}$ Khon Kaen University, Plant Breeding Research Center for Sustainable Agriculture, Khon Kaen, \\ THAILAND \\ ${ }^{4}$ Mahasarakham University, Faculty of Technology, Department of Agricultural Technology, \\ Mahasarakham, THAILAND \\ *Corresponding author: bsuriharn@gmail.com
}

Received: 22.05.2014

\begin{abstract}
Selection of purple waxy corn genotypes for high and stable anthocyanin content in corn cobs is important for breeding programs and anthocyanin production. The objectives of this study were to evaluate the effects of location, genotype and their interaction on anthocyanin content and antioxidant activities and to identify purple waxy corn genotypes with high and stable anthocyanin content. Five purple waxy corn and a white waxy corn genotypes were evaluated in a randomized complete block design with three replications at four locations with different elevations in Thailand. Location (L), genotype (G) and GxL interaction were significant for all characters. Waxy corn grown in Nakhon Ratchasima had the highest total anthocyanin content (TAC), cyanidin 3-glucoside (C3G), pelargonidin 3-glucoside (Pg3G), and peonidin 3-glucoside (Pn3G), DPPH radical scavenging activity of phenolics (DPPH) and Trolox equivalent antioxidant potential (TEAC). Genotype KNDM4 had the highest TAC, Pg3G, Pn3G and DPPH. Its regression coefficient $\left(b_{i}\right)$ was close to one but it had the highest $\mathrm{Sd}^{2}$, indicating specific adaptation to favorable environments. KNDM4 genotype performed better than other genotypes at unfavorable environments for all studied traits. This information is useful for breeding programs and anthocyanin production from purple waxy corn.
\end{abstract}

Keywords: Anthocyanin production, Different elevations, Favorable environments, Regression coefficient, Specific adaptation

\section{INTRODUCTION}

Waxy corn (Zea mays L. var. ceratina) is an important vegetable crop in East and Southeast Asia including China, Vietnam, Cambodia, Taiwan, Korea and Thailand. The world production of vegetable waxy corn is low compared to field corn and sweet corn. It is popular among people in these countries because of its glutinous starch in endosperm due to high amylopectin. Unlike field corn, waxy corn has received little interest for genetic improvement through breeding. The increase in demand for waxy corn and market potential arouses more attention from breeders to improve waxy corn. There are numerous special cultivars that contain colored pigments and give rise to numerous varieties of black and purple corn. Purple corn produced the anthocyanin pigment throughout the plant, especially high in the husk and cob regions, although anthocyanin levels varied significantly among different plant parts ( $\mathrm{Li}$ et al., 2008).

Anthocyanins have health benefits in reducing the incidence of cardiovascular disease, cancer, hyperlipidemias and other chronic diseases (de PascualTeresa and Sanchez-Ballesta, 2008; Wang and Stoner, 2008). Purple waxy corn genotypes had the highest total anthocyanin and antioxidant activity in seed at both immature and harvesting stages in comparison with white waxy corn, super sweet corn and field corn (Khampas et al., 2013). Recently, a study showed that purple waxy corn is a source of anthocyanins with a protective property against diabetic cataract (Thiraphatthanavong et al., 2014). Kernels and cobs of purple corn possess an excellent antioxidant activity, and the application of these natural food colorants by the food industry would be increased 
considerably (Yang and Zhai, 2010). Corn cob contributed the most in phenolic compounds and antioxidant capacity, and can be considered as excellent novel sources of natural antioxidants for the functional food and dietary supplement markets (Cevallos-Casals and CisnerosZevallos, 2003). This makes it more attractive for nutraceutical and functional food market.

High and stable yield across a range of environments is the primary goal of plant breeding programs. Recently, breeding for high anthocyanins is a priority of waxy corn breeding program at Khon Kaen University as this character defines it possible use as colorants and functional food. Most previous studies on stability and genotype by environment interaction in agronomic traits of cereal crops have focused on yield and the studies on quality traits such anthocyanin content and antioxidant activity are still lacking (Altay, 2012; Mitrović et al., 2012; Mohammadi et al., 2012). In wheat, cultivars Kate A1 and Mufitbey were found to be the most stable genotypes for all the environments whereas cultivar Gerek-79 was found to be the best performer for under poor soil and weather conditions (Altay, 2012), and significant genotype $\times$ environment interactions were observed among wheat genotypes (Altay, 2012; Mohammadi et al., 2012). In maize, environment accounted for the largest portion $(77.83 \%)$ of total variation in grain yield, whereas genotype and genotype by environment accounted for $30 \%$ of total variation (Mitrović et al., 2012).

Several factors such as genetic, agronomic, $\mathrm{pH}$, temperature, light intensity, type of light, and metallic ions, processing and storage affect anthocyanin stability (Bordignon-Luiz et al., 2007; de Rosso and Mercadante 2007; Mollov et al., 2007; Veigas et al., 2007; de PascualTeresa and Sanchez-Ballesta, 2008). Anthocyanin was mainly affected by $\mathrm{pH}$ and temperature (Cevallos-Casals and Cisneros-Zevallos, 2004). However, Zhao et al. (2008) found that anthocyanin in five Chinese purple corn hybrids was rather stable across a wide range of temperatures and times. Soil potassium concentration and population density did not significantly affect anthocyanin concentration in cobs, but growing location affected anthocyanin levels and the percentage of anthocyanins to total phenolics (Jing et al., 2007).

Table 2. The testing locations used in this study.

\begin{tabular}{|c|c|c|c|}
\hline Locations & $\begin{array}{l}\text { Geographical } \\
\text { coordinates }\end{array}$ & $\begin{array}{l}\text { Elevations } \\
\text { (masl) }\end{array}$ & Planting date \\
\hline Saraburi & $\mathrm{N} 14^{\circ} 43^{\prime} \mathrm{E} 100^{\circ} 47^{\prime}$ & 120 & Dec 2012 \\
\hline Khon Kaen & $\mathrm{N} 16^{\circ} 28^{\prime} \mathrm{E} 102^{\circ} 49^{\prime}$ & 200 & Nov 2012 \\
\hline Nakhon Ratchasima & $\mathrm{N} 14^{\circ} 30^{\prime} \mathrm{E} 101^{\circ} 30^{\prime}$ & 356 & Dec 2012 \\
\hline Chiang Rai & $\mathrm{N} 20^{\circ} 24^{\prime} \mathrm{E} 99^{\circ} 53^{\prime}$ & 380 & Feb 2013 \\
\hline
\end{tabular}

The genotypes were grown in four-row plots with $5 \mathrm{~m}$ long and spacing of $0.80 \mathrm{~m}$ between rows and $0.25 \mathrm{~m}$ between plants within rows. Recommended cultural practices were used for all locations. The crop at all location was well-irrigated for optimum growth and yield. Sprinkler irrigation was available at the locations in Khon
However, effects of various factors such as genotypes, environments and their interaction on purple waxy corn anthocyanin have not been adequately studied. The objectives of this study were to evaluate the effects of location, genotype and their interaction on anthocyanin content and antioxidant activities and to identify purple waxy corn genotypes with high and stable anthocyanin content. The information obtained from this study is important for breeding of waxy corn for high anthocyanin content and antioxidant activity and selection of locations for production of waxy corn for use as raw material for functional food products.

\section{MATERIALS AND METHODS}

\section{Plant Materials}

Five purple waxy corn genotypes (KGW1, KGW2, KGW3, KNDM4 and Fancy 111) and one white waxy corn genotype (Fancy 121) were used as plant material in the study (Table 1). Most of them are $F_{1}$ hybrids except for KNDM4, which is an open-pollinated variety (Hussanun et al., 2014).

Table 1. The waxy corn varieties used in this study.

\begin{tabular}{llll}
\hline Genotypes & Seed color & Cob color & Types \\
\hline 1. KGW1 & Purple & Purple & Hybrid \\
2. KGW2 & Purple & Purple & Hybrid \\
3. KGW3 & Purple & Purple & Hybrid \\
4. KNDM4 & Purple & Purple & Opened-pollinated \\
5. FANCY $111^{1 /}$ & Purple & Purple & Hybrid \\
6. FANCY $121^{1 /}$ & White & White & Hybrid \\
\hline${ }^{1 /}$ Commercial variety & &
\end{tabular}

\section{Field Experiment}

Six genotypes of waxy corn were evaluated in a randomized complete block design with three replications at four locations (Saraburi, Khon Kaen, Nakhon Ratchasima and Chiang Rai) with differences in elevations from 120 to 380 meters above sea level in the dry season 2012/13. These locations represented waxy corn growing areas in Thailand from the central plain to the North of Thailand. The details of locations were presented in Table 2.

Kaen, Nakhon Ratchasima and Chiang Rai, whereas furrow irrigation was performed in Saraburi.

15-15-15 Fertilizer of N-P-K as basal dose at the rate of $171 \mathrm{~kg} \mathrm{ha}^{-1}$ was incorporated into the soil during soil preparation. Two splits of the fertilizer at the rate of 93.75 $\mathrm{kg} \mathrm{ha}^{-1}$ plus urea (46-0-0) at the rate of $93.75 \mathrm{~kg} \mathrm{ha}^{-1}$ for 
first split and the fertilizer at the rate of $125 \mathrm{~kg} \mathrm{ha}^{-1}$ plus urea at the rate of $62.5 \mathrm{~kg} \mathrm{ha}^{-1}$ for second split were applied to the crop at 14 days after planting (DAP) and 30 DAP, respectively. At flowering stage, 13-13-21fertilizer was applied at the rate of $156.25 \mathrm{~kg} \mathrm{ha}^{-1}$. Therefore, total dose of fertilizers consisted of $150.65 \mathrm{~kg} \mathrm{ha}^{-1}$ nitrogen, $78.78 \mathrm{~kg} \mathrm{ha}^{-1}$ phosphorus and $91.27 \mathrm{~kg} \mathrm{ha}^{-1}$ potassium, respectively. Weather and soil data for all locations were presented in Table 3 and Table 4, respectively.

Table 3. Weather data at four locations.

\begin{tabular}{|c|c|c|c|c|}
\hline $\begin{array}{l}\text { Days after } \\
\text { planting }\end{array}$ & $\begin{array}{l}\text { Average Temperature } \\
\left({ }^{\circ} \mathrm{C}\right)\end{array}$ & $\begin{array}{l}\text { Solar } \\
\text { radiation } \\
\left(\mathrm{MJ} \mathrm{m}^{-2} \text { day }^{-1}\right)\end{array}$ & $\begin{array}{l}\text { Total rainfall } \\
(\mathbf{m m})\end{array}$ & $\begin{array}{l}\text { Relative humanity } \\
(\%)\end{array}$ \\
\hline \multicolumn{5}{|l|}{ Saraburi } \\
\hline $0-30$ & 28.5 & 15.3 & 49 & 68.7 \\
\hline $31-60$ & 27.1 & 17.8 & 0 & 62.7 \\
\hline $61-90$ & 29.7 & 18.9 & 3 & 66.8 \\
\hline mean & 28.4 & 17.3 & & 66.1 \\
\hline \multicolumn{5}{|l|}{ Khon Kaen } \\
\hline $0-30$ & 26.9 & 17.1 & 23 & 60.0 \\
\hline $31-60$ & 23.7 & 17.6 & 0 & 52 \\
\hline $61-90$ & 26.7 & 17.1 & 6 & 52 \\
\hline mean & 25.8 & 17.3 & & 78.6 \\
\hline \multicolumn{5}{|c|}{ Nakhon Ratchasima } \\
\hline $0-30$ & 25.1 & 16.9 & 5 & 68.4 \\
\hline $31-60$ & 25.0 & 18.2 & 46 & 62.4 \\
\hline $61-90$ & 26.7 & 19.7 & 42 & 71.1 \\
\hline mean & 25.6 & 18.3 & & 67.3 \\
\hline \multicolumn{5}{|l|}{ Chiang Rai } \\
\hline $0-30$ & 25.2 & 16.9 & 53 & 74.3 \\
\hline $31-60$ & 27.1 & 19.8 & 8 & 71.4 \\
\hline $61-90$ & 28.8 & 20.8 & 84 & 62.3 \\
\hline mean & 27.0 & 19.2 & & 69.4 \\
\hline
\end{tabular}

Table 4. Soil physical and chemical properties.

\begin{tabular}{lllllllll}
\hline Locations & Soil types & $\begin{array}{l}\mathbf{p H} \\
\left.\mathbf{( 1 : 1} \mathbf{H}_{\mathbf{2}} \mathbf{0}\right)\end{array}$ & $\begin{array}{l}\mathbf{E C} \\
\left.\mathbf{( 1 : 5} \mathbf{H}_{\mathbf{2}} \mathbf{0}\right) \\
(\mathbf{d S} / \mathbf{m})\end{array}$ & $\begin{array}{l}\text { Organic } \\
\text { Matter } \\
(\boldsymbol{\%})\end{array}$ & $\begin{array}{l}\text { Total } \\
\text { nitrogen } \\
(\mathbf{\%})\end{array}$ & $\begin{array}{l}\text { Available } \\
\text { Phosphorus } \\
(\mathbf{m g} / \mathbf{k g})\end{array}$ & $\begin{array}{l}\text { Available } \\
\mathbf{p o t a s s i u m} \\
(\mathbf{m g} / \mathbf{k g})\end{array}$ & $\begin{array}{l}\text { Available } \\
\mathbf{c a l c i u m} \\
(\mathbf{m g} / \mathbf{k g})\end{array}$ \\
\hline Saraburi & Sandy loam & 7.4 & 0.09 & 1.22 & 0.06 & 234 & 155 & 2,432 \\
Khon Kaen & Sandy & 4.9 & 0.01 & 0.73 & 0.03 & 307 & 139 & 54 \\
$\begin{array}{l}\text { Nakhon } \\
\text { Ratchasima }\end{array}$ & Loamy sand & 7.1 & 0.13 & 2.49 & 0.13 & 52 & 162 & 3,137 \\
Chiang Rai & Loamy sand & 5.6 & 0.08 & 3.40 & 0.09 & 45 & 149 & 593 \\
\hline
\end{tabular}

Corn cobs were collected at harvest maturity stage (R6) or 90 days after planting and stored at room temperature for analysis of anthocyanin and antioxidant activity. Data were recorded for total anthocyanin content (TAC), cyanidin 3-glucoside (C3G), pelargonidin 3glucoside $(\mathrm{Pg} 3 \mathrm{G})$, and peonidin 3-glucoside (Pn3G), DPPH radical scavenging activity of phenolics (DPPH) and the Trolox equivalent anti-oxidant potential (TEAC) as described by Yang et al. (2008).

\section{Sample extraction}

The portions of $0.5 \mathrm{~g}$ cob powder samples were weighted and pounded to fine powder using mortar and pestle. The extraction method used for TAC and antioxidant activity analysis was modified from the method reported previously (Yang et al., 2008). The samples were extracted in $25 \mathrm{ml}$ of methanol containing $1 \% 1 \mathrm{M}$ citric acid in falcon tubes. The mixtures were vortexed and stored at $4{ }^{\circ} \mathrm{C}$ for 24 hours. The homogenates were centrifuged at $5000 \mathrm{rpm}$ at $4{ }^{\circ} \mathrm{C}$ for 15 minutes. After centrifugation, the mixtures were acquired by filtration through Whatman No.1 filter papers, adjusted to $25 \mathrm{ml}$ and stored in dark room at $-20{ }^{\circ} \mathrm{C}$ until analysis for TAC and antioxidant activity.

\section{Analysis of total anthocyanin content (TAC)}

TAC was quantified by $\mathrm{pH}$ differential method (Giusti and Wrolstad, 2001). The absorbance of diluted extracts was measured to detect anthocyanins level at $510 \mathrm{~nm}$ and $700 \mathrm{~nm}$ with UV-Visible Spectrophotometer (model Specord 250 plus, Analytik jena, Germany) against a blank cell filled with distilled water. The absorbance was calculated as $\mathrm{Abs}=\left(\mathrm{Abs}_{510}-\mathrm{A}_{700}\right) \mathrm{pH} 1.0-\left(\mathrm{Abs}_{510}-\mathrm{A}_{700}\right)$ $\mathrm{pH}$ 4.5. Then monomeric anthocyanin pigment in samples was calculated as; 
Monomeric anthocyanin pigment $=($ Abs $\times$ MW $x$ DF $\mathrm{X} 1000) /(\varepsilon \times 1)$,

Where MW is the molecular weight of cyanidin 3glucoside (MW of $449.2 \mathrm{~g} / \mathrm{mol}$ ), DF is dilution factor of the sample and $\varepsilon$ is the molar extinction coefficient (Equal to $26900 \mathrm{M}^{-1} \mathrm{~cm}^{-1}$ ).

Anthocyanin levels were presented in $\mathrm{mg}$ of cyanidin 3-glucoside equivalents (CGE) per $100 \mathrm{~g}$ of dry weight (DW).

\section{HPLC analysis of anthocyanin components}

Total anthocyanin content was determined by the method described by Kim et al. (2007) with minor modification, and individual anthocyanin components were quantified with high-performance liquid chromatography (HPLC), Shimadzu LC-20AC pushes (Shimadzu Co., Kyoto, Japan), SPD-M20A with a photodiode array detector (Waters, USA). A XselectCHS C-18 line $(4.6 \mathrm{~mm} \times 250 \mathrm{~mm}$, i.d. $5 \mu \mathrm{m})$. The extracts of cob samples were filtered through a $0.22 \mu \mathrm{m}$ filter at 30 ${ }^{\circ} \mathrm{C}$. The anthocyanins were eluted at $1 \mathrm{~mL} / \mathrm{min}$ using gradient system consisting of two solvents: (A) acidified methanol (methanol $0.1 \% \mathrm{HCl}, 85: 15, \mathrm{v} / \mathrm{v}$ ) and (B) $10 \%$ formic acid. The gradient elutions of solvent B were performed as follows: for $0.0-0.5 \mathrm{~min}(80 \%), 0.5-9.5 \mathrm{~min}$ (15\%), 9.5-10.0 $\min (5 \%), 10.0-15.0 \mathrm{~min}(80 \%)$, and 15.0-20.0 $\mathrm{min}(80 \%)$. The divided solutions were consequently detected and identified at $520 \mathrm{~nm}$ for chromatographic retention times. Three purified anthocyanins consist of cyanidin 3-glucoside, pelargonidin 3-glucoside, and peonidin 3-glucoside and one anthocyanidin (cyanidin chloride) (Sigma, USA) were used for quantification.

The purified anthocyanins extractions were utilized to aid the identification of individual anthocyanins. The standard solutions were prepared in acidified methanol (pH 1) by weighing exactly $200-300 \mu \mathrm{g}$ in $200 \mu \mathrm{L} ; 20 \mu \mathrm{L}$ of standard solutions and then diluted to $500 \mu \mathrm{L}$ to prepare working standard. The standard anthocyanins revealed a linear relationship with a HPLC optimum peak area with a concentration range of $0.0-1.0 \mu \mathrm{g}$. The coefficient of dedication $\left(\mathrm{r}^{2}\right)$ varied from 0.9933 to 0.9998 for a mixture of purified anthocyanins, which were divided by HPLC using 5,10 , and $15 \mu \mathrm{L}$ of operating standard solution.

\section{Analysis of antioxidant activity}

DPPH radical scavenging activity of methanolic extracts was determined according to $\mathrm{Xu}$ et al. (2010). Briefly, $0.5 \mathrm{~mL}$ of sample extract was added and mixed with $4.5 \mathrm{~mL}$ of $60 \mu \mathrm{M}$ DPPH demolished in methanol. The mixture was shaken thoroughly and allowed to stand for half an hour in the dark room. The absorbance was detected at $517 \mathrm{~nm}$ against the solvent blank. Trolox solution (100-1000 $\mu \mathrm{M})$ was used as a reference conventional. The outcomes were provided in micromoles Trolox equivalents (TE) per $g$ of DW.

Analysis of Trolox equivalent antioxidant capacity (TEAC) measured by the reduction in radical cation of
ABTS by anti-oxidants was carried out as previously described by Jemai et al. (2009). Briefly, ABTS+ radical cation was conducted with a result of $7 \mathrm{mmol} / \mathrm{L}$ ABTS and $2.45 \mathrm{mmol} / \mathrm{L}$ potassium per sulfate. The combination was allowed to stay in dark room at ambient temperature 16-24 hours prior to use and should be used within 2 days. The ABTS solution was diluted with methanol for absorbance of $0.700 \pm 0.050$ at $734 \mathrm{~nm}$. All samples were diluted appropriately to provide $20-80 \%$ inhibition of the blank absorbance. $50 \mu \mathrm{L}$ of the diluted extract was taken by a pipette and combined with $1.9 \mathrm{~mL}$ of diluted ABTS solution. The analysis of the combination was performed in three replications. The combination was allowed to stand for 6 min at ambient temperature and the absorbance was instantly measured at $734 \mathrm{~nm}$. Trolox solution (100$1000 \mu \mathrm{M}$ ) was used as a reference point. The outcomes were indicated as micromoles Trolox equivalents (TE) per $\mathrm{g}$ of DW.

\section{Statistical Analysis}

Data for each location were analyzed separately and error variances were tested for variance homogeneity. As variances were homogeneous and the differences of error variances were not larger than 3 folds, then combined analysis of variance was performed across the locations. Linear regression was carried out to study stability of corn genotypes by plotting cultivar's means against environmental means for each genotype as described by Eberhart and Russell (1966). Means were compared statistically using least significant difference (LSD) at $P \leq 0.05$.

\section{RESULTS AND DISCUSSION}

\section{Variations in anthocyanin and antioxidant activity}

Location (L), genotype $(\mathrm{G})$ and GxL interaction were significant $(\mathrm{P} \leq 0.01)$ for total anthocyanin content (TAC), cyanidin 3-glucoside (C3G), pelargonidin 3-glucoside (Pg3G), and peonidin 3-glucoside (Pn3G), DPPH radical scavenging activity of phenolics (DPPH) and the Trolox equivalent anti-oxidant potential (TEAC) (Table 5). Location contributed to large portions of total variations in TAC (44\%), C3G (56\%), Pg3G (60\%), Pn3G (62\%), DPPH $(52 \%)$ and TEAC (57\%).

Genotype contributed to relatively large portion of total variation in TAC (42\%), but genotype contributed to rather small portions of total variations in $\mathrm{C} 3 \mathrm{G}(18 \%)$, Pg3G (20\%), Pn3G (2\%), DPPH (24\%) and TEAC (11\%). $\mathrm{G} \times \mathrm{L}$ interactions contributed to medium to small portions of total variations in TAC (13\%), C3G (25\%), Pg3G (20\%), Pn3G (15\%), DPPH (22\%) and TEAC $(32 \%)$.

Anthocyanins are phytochemicals that commonly occur in many cereal and fruit crops, and the trait is quantitatively inherited (Vizzotto et al., 2007). In corn, anthocyanins are present in all tissues and found at high concentrations in kernel skin and cobs (Moreno et al., 2005). In fruit crops such as grape, grapes may be either white or colored, ranging from the lightest pink to the darkest purple tones according to the amount of 
anthocyanin accumulated in the berry skin, which is a crucial trait for both wine quality and human nutrition (Fournier-Level et al., 2009). In peach, anthocyanin content, phenolic content, and antioxidant activity were higher in red-flesh than in light-colored flesh peaches (Vizzotto et al., 2007). Genetic variation in anthocyanins has been reported in maize (Chander et al., 2008), grape
(Fournier-Level et al., 2009) and wheat (Knievel et al., 2009). The results indicated that selection for high TAC would be possible among purple waxy corn genotypes. Variation among locations also indicated the importance of selection for the best location for anthocyanin production in corn.

Table 5. Mean squares for total anthocyanin content (TAC), cyanidin 3-glucoside (C3G), pelargonidin 3-glucoside (Pg3G), and peonidin 3-glucoside (Pn3G), DPPH radical scavenging activity of phenolics (DPPH) and the Trolox equivalent anti-oxidant potential (TEAC) of six waxy corn lines/cultivars.

\begin{tabular}{|c|c|c|c|c|c|c|c|}
\hline \multirow{2}{*}{ SOV } & \multirow[b]{2}{*}{ df } & TAC & \multirow{2}{*}{$\begin{array}{c}\text { C3G } \\
\mathrm{mg} / 100 \mathrm{gDW}\end{array}$} & \multirow{2}{*}{$\begin{array}{c}\text { Pg3G } \\
\text { mg/100gDW }\end{array}$} & \multirow{2}{*}{$\begin{array}{c}\text { Pn3G } \\
\text { mg/100gDW }\end{array}$} & \multirow{2}{*}{$\begin{array}{c}\text { DPPH } \\
\mu \mathrm{mol} / \mathrm{gDW}\end{array}$} & \multirow{2}{*}{$\begin{array}{c}\text { TEAC } \\
\mu \mathrm{mol} / \mathrm{gDW}\end{array}$} \\
\hline & & mg/100gDW & & & & & \\
\hline Location (L) & 3 & $\begin{array}{c}1,004,062 * * \\
(44)\end{array}$ & $\begin{array}{c}60,464 * * \\
(56)\end{array}$ & $\begin{array}{c}6,320 * * \\
(60)\end{array}$ & $\begin{array}{c}1,564 * * \\
(62)\end{array}$ & $\begin{array}{c}179.4 * * \\
(52)\end{array}$ & $\begin{array}{c}86.1^{* *} \\
(57)\end{array}$ \\
\hline Replication (R)/L (a) & 8 & 432 & 50 & 6 & 2 & 1.4 & 0.1 \\
\hline Genotype (G) & 4 & $\begin{array}{c}15,975^{* *} \\
(42)\end{array}$ & $\begin{array}{c}14,582 * * \\
(18)\end{array}$ & $\begin{array}{c}1,542 * * \\
(20)\end{array}$ & $\begin{array}{l}411 * * \\
(2)\end{array}$ & $\begin{array}{l}61.4 * * \\
(24)\end{array}$ & $\begin{array}{c}12.3 * * \\
(11)\end{array}$ \\
\hline $\mathbf{G} \times \mathbf{L}$ & 12 & $\begin{array}{c}75,107 * * \\
(13)\end{array}$ & $\begin{array}{c}6,596^{* * *} \\
(25)\end{array}$ & $\begin{array}{l}512 * * \\
(20)\end{array}$ & $\begin{array}{l}96 * * \\
(15)\end{array}$ & $\begin{array}{c}18.5 * * \\
(22)\end{array}$ & $\begin{array}{c}12.0^{* * *} \\
(32)\end{array}$ \\
\hline Error (b) & 32 & 2,726 & 67 & 5 & 3 & 0.4 & 0.1 \\
\hline C.V. (\%) (a) & & 4.1 & 15.6 & 14.0 & 12.5 & 8.0 & 7.5 \\
\hline C.V. (\%) (b) & & 10.3 & 18.1 & 12.0 & 15.2 & 4.1 & 5.4 \\
\hline
\end{tabular}

** Highly significant difference at $p \leq 0.01$

Values in parenthesis are percentages of sum squares.

\section{Effects of location and genotype on anthocyanins and antioxidant activity}

Location was the main source of variation in TAC, C3G, Pg3G, Pn3G, DPPH and TEAC of five purple waxy corns and one white waxy corn. Nakhon Ratchasima had the highest TAC of $730 \mathrm{mg} / 100 \mathrm{gDW}$ followed by 418 $\mathrm{mg} / 100 \mathrm{gDW}$ in Saraburi, whereas Khon Kaen and Chiang Rai had rather low TAC, accounting for 275 and $271 \mathrm{mg} / 100 \mathrm{gDW}$, respectively (Table 6). Similar patterns were also observed for C3G, Pg3G, Pn3G and DPPH. For these parameters, Nakhon Ratchasima was still highest followed by Saraburi, whereas Khon Kaen and Chiang Rai were similar and lower than Nakhon Ratchasima and Saraburi. Nakhon Ratchasima was also highest for TAEC followed by Khon Kaen, Saraburi and Chiang Rai, respectively.

In general, the highest TAC and anthocyanin components in corn cobs were found in Nakhon Ratchasima compared to the nearest locations in Khon Kaen and Saraburi. Nakhon Ratchasima is located at higher alleviation and had lower temperature during growing season and lower phosphorus. Low temperature and low phosphorus might be the cause of the high TAC and its components.

Low temperature induced anthocyanin synthesis in maize seedlings (Christie et al., 1994). Anthocyanin concentration increased rapidly during low temperature in apple and peach shoots (Leng et al., 2000). Anthocyanins and phenolics contents were enhanced with higher light intensity and lower temperature in potato tubers (Reyes et al., 2004). Visible and UVB radiation, cold temperatures and water stress has been shown to induce anthocyanin synthesis in plant tissue (Chalker-Scott, 1999).

However, low temperatures in the absence of either visible light or UVB prevent anthocyanin biosynthesis (Janda et al., 1996; Oren-Shamir and Levi-Nissim, 1997). Wang and Zheng (2001) also found that high temperature (30/22 day/night ${ }^{\circ} \mathrm{C}$ ) condition enhanced phenolic acid, flavonols, and anthocyanins in strawberry.

Phosphorus deficiency induces anthocyanins accumulation in maize (Cobbina and Miller, 1987). Antocyanin content was increased and growth was decreased on nitrogen and phosphorus deficiency in Cruciferous (Hodges and Nozzolillo 1996). However, Chiang Rai also had low phosphorus but it had the lowest anthocyanins possibly due to high temperature and high solar radiation during reproductive periods. It should be note that stresses of low temperature and low phosphorus were the factors enhancing anthocyanin accumulation.

Nakhon Ratchasima (low temperature and low phosphorus) also had the highest antioxidant activities (DPPH and TEAC) but Chiang Rai (high temperature and low phosphorus) had the lowest highest antioxidant activities. These results were in agreement with previous study of Lachman et al. (2008) who reported that low temperature during vegetative period showed high antioxidant activity in potatoes. 
Table 6. Means for total anthocyanin content (TAC), cyanidin 3-glucoside (C3G), pelargonidin 3-glucoside (Pg3G), and peonidin 3glucoside (Pn3G), DPPH radical scavenging activity of phenolics (DPPH) and the Trolox equivalent anti-oxidant potential (TEAC) of six waxy corn lines/cultivars evaluated in four locations 2012/13.

\begin{tabular}{|c|c|c|c|c|}
\hline & Saraburi & Khon Kaen & Nakhon Ratchasima & Chiang Rai \\
\hline \multicolumn{5}{|c|}{ TAC $(\mathrm{mg} / 100 \mathrm{gDW})$} \\
\hline KGW1 & $247^{j}$ & $671^{\mathrm{m}}$ & $609^{\mathrm{e}}$ & $129^{\mathrm{KI}}$ \\
\hline KGW2 & $449^{\mathrm{g}}$ & $341^{\mathrm{h}}$ & $982^{\mathrm{c}}$ & $373^{\mathrm{h}}$ \\
\hline KGW3 & $328^{\text {hi }}$ & $263^{\mathrm{ij}}$ & $547^{\mathrm{ef}}$ & $330^{\mathrm{hi}}$ \\
\hline KNDM4 & $1,132^{\mathrm{ab}}$ & $826^{\mathrm{d}}$ & $1,166^{\mathrm{a}}$ & $490^{\mathrm{fg}}$ \\
\hline FANCY111 & $346^{\mathrm{h}}$ & $148^{\mathrm{k}}$ & $1,076^{\mathrm{b}}$ & $302^{\text {hij }}$ \\
\hline FANCY121 & $4^{\mathrm{m}}$ & $6^{\mathrm{m}}$ & $3^{\mathrm{m}}$ & $2^{\mathrm{m}}$ \\
\hline Means & $418^{\mathrm{B}}$ & $275^{\mathrm{C}}$ & $730^{\mathrm{A}}$ & $271^{\mathrm{C}}$ \\
\hline \multicolumn{5}{|c|}{ C3G (mg/100g DW) } \\
\hline KGW1 & $5^{\mathrm{fg}}$ & $4^{\mathrm{fg}}$ & $37^{\mathrm{d}}$ & $1^{g}$ \\
\hline KGW2 & $27^{\mathrm{de}}$ & $9^{\text {fg }}$ & $246^{\mathrm{a}}$ & $2^{\mathrm{g}}$ \\
\hline KGW3 & $16^{\mathrm{ef}}$ & $7^{\mathrm{fg}}$ & $93^{b}$ & $3^{g}$ \\
\hline KNDM4 & $96^{\mathrm{b}}$ & $23^{\mathrm{e}}$ & $246^{\mathrm{a}}$ & $5^{\mathrm{fg}}$ \\
\hline FANCY111 & $9^{f}$ & $2^{\mathrm{g}}$ & $72^{c}$ & $1^{\mathrm{g}}$ \\
\hline FANCY121 & $1^{\mathrm{g}}$ & $1^{g}$ & $1^{g}$ & $1^{\mathrm{g}}$ \\
\hline Means & $26^{\mathrm{B}}$ & $8^{\mathrm{C}}$ & $116^{\mathrm{A}}$ & $2^{\mathrm{D}}$ \\
\hline \multicolumn{5}{|c|}{ Pg3G (mg/100g DW) } \\
\hline KGW1 & $3^{\text {hi }}$ & $3^{\text {hi }}$ & $9^{f}$ & $2^{\mathrm{hi}}$ \\
\hline KGW2 & $11^{\mathrm{f}}$ & $5^{\mathrm{gh}}$ & $54^{\mathrm{c}}$ & $3^{\text {hi }}$ \\
\hline KGW3 & $10^{\mathrm{f}}$ & $5^{\text {ghi }}$ & $29^{\mathrm{d}}$ & $3^{\text {hi }}$ \\
\hline KNDM4 & $30^{\mathrm{d}}$ & $15^{\mathrm{e}}$ & $86^{\mathrm{a}}$ & $7^{\mathrm{fg}}$ \\
\hline FANCY111 & $16^{\mathrm{e}}$ & $5^{\text {gh }}$ & $63^{\mathrm{b}}$ & $3^{\text {hi }}$ \\
\hline FANCY121 & $2^{\text {hi }}$ & $2^{\mathrm{i}}$ & $2^{\text {hi }}$ & $2^{\text {hi }}$ \\
\hline Means & $12^{\mathrm{B}}$ & $6^{\mathrm{C}}$ & $41^{\mathrm{A}}$ & $3^{\mathrm{D}}$ \\
\hline \multicolumn{5}{|c|}{ Pn3G (mg/100g DW) } \\
\hline KGW1 & $3^{\text {ghi }}$ & $3^{\text {ghi }}$ & $5^{\mathrm{fg}}$ & $2^{i}$ \\
\hline KGW2 & $15^{\mathrm{c}}$ & $7^{\mathrm{ef}}$ & $35^{\mathrm{a}}$ & $3^{\text {ghi }}$ \\
\hline KGW3 & $9^{\text {de }}$ & $5^{\mathrm{fg}}$ & $26^{\mathrm{b}}$ & $3^{\text {ghi }}$ \\
\hline KNDM4 & $26^{\mathrm{b}}$ & $11^{\mathrm{d}}$ & $35^{\mathrm{a}}$ & $5^{\text {fgh }}$ \\
\hline FANCY111 & $9^{\text {de }}$ & $3^{\text {ghi }}$ & $28^{\mathrm{b}}$ & $2^{\text {hi }}$ \\
\hline FANCY121 & $2^{\mathrm{i}}$ & $1 \mathrm{i}$ & $2^{\mathrm{i}}$ & $2^{\mathrm{i}}$ \\
\hline Means & $11^{\mathrm{B}}$ & $5^{\mathrm{C}}$ & $22^{\mathrm{A}}$ & $3^{\mathrm{D}}$ \\
\hline \multicolumn{5}{|c|}{ DPPH $(\mu \mathrm{mol} / \mathrm{gDW})$} \\
\hline KGW1 & $11^{1}$ & $10^{1}$ & $18^{\mathrm{cde}}$ & $8^{\mathrm{jk}}$ \\
\hline KGW2 & $17^{\mathrm{ef}}$ & $14^{\mathrm{h}}$ & $18^{\mathrm{cd}}$ & $10^{\mathrm{i}}$ \\
\hline KGW3 & $17^{\mathrm{de}}$ & $13^{\mathrm{h}}$ & $19^{\mathrm{cd}}$ & $9^{\mathrm{j}}$ \\
\hline KNDM4 & $22^{\mathrm{a}}$ & $18^{\mathrm{cd}}$ & $15^{\mathrm{g}}$ & $16^{\mathrm{fg}}$ \\
\hline FANCY111 & $19^{c}$ & $13^{\mathrm{h}}$ & $21^{\mathrm{b}}$ & $11^{\mathrm{i}}$ \\
\hline FANCY121 & $5^{1}$ & $5^{1}$ & $4^{1}$ & $7^{\mathrm{k}}$ \\
\hline Means & $15^{\mathrm{A}}$ & $12^{\mathrm{B}}$ & $16^{\mathrm{A}}$ & $10^{\mathrm{C}}$ \\
\hline \multicolumn{5}{|c|}{ TEAC $(\mu \mathrm{mol} / \mathrm{gDW})$} \\
\hline KGW1 & $0.8^{\mathrm{mn}}$ & $2.8^{\mathrm{h}}$ & $5.3_{\mathrm{e}}$ & $1.3^{\mathrm{kT}}$ \\
\hline KGW2 & $6.4^{\mathrm{d}}$ & $3.8^{\mathrm{g}}$ & $8.1^{\mathrm{b}}$ & $1.3^{\mathrm{lk}}$ \\
\hline KGW3 & $7.3^{\mathrm{c}}$ & $3.7^{\mathrm{g}}$ & $6.9^{c}$ & $2.2^{\mathrm{ij}}$ \\
\hline KNDM4 & $1.1^{\mathrm{lm}}$ & $5.7^{\mathrm{e}}$ & $8.2^{\mathrm{b}}$ & $4.2^{\mathrm{f}}$ \\
\hline FANCY111 & $1.4^{\mathrm{k}}$ & $2.5^{\mathrm{hi}}$ & $10.2^{\mathrm{a}}$ & $2.1^{\mathrm{j}}$ \\
\hline FANCY121 & $0.3^{\mathrm{op}}$ & $0.0^{\mathrm{p}}$ & $0.0^{\mathrm{p}}$ & $0.5^{\mathrm{no}}$ \\
\hline Means & $2.9^{\mathrm{B}}$ & $3.1^{\mathrm{B}}$ & $6.4^{\mathrm{A}}$ & $1.9^{\mathrm{C}}$ \\
\hline
\end{tabular}

As the interactions between location and genotype were significant for all parameters, identification of the best genotypes for each parameter was difficult. The varieties that showed good performance in one location did not perform well in other locations. However, KNDM4 showed consistently the highest values for TAC,
C3G, Pg3G and Pn3G across locations. High values for these parameters in KNDM4 would be due to the fact that it is an open-pollinated variety and other hybrids had one parent with white kernels. For DPPH, KNDM4 was highest in Saraburi, Khon Kaen and Chiang Rai, whereas FANCY111 was highest in Nakhon Ratchasima. For 
TEAC, KNDM4 was the winner in two locations in Khon Kaen and Chiang Rai. FANCY111 was still highest in Nakhon Ratchasima, whereas KGW3 was highest in Saraburi. FANCY111, which is the waxy corn, showed consistently the lowest values for all parameters across locations.

\section{Stability analysis for anthocyanins and antioxidant activity}

The genotypes with stable yield should have high mean yield across locations, regression coefficient close to one $\left(b_{i}=1\right)$ and deviation from regression $\left(\mathrm{Sd}^{2}\right)$ close to zero (Eberhart and Russell, 1966). KNDM4 had the highest TAC (903 mg/100 $\mathrm{gDW}$ ) and regression coefficient close to one (0.9), but it showed high deviation from regression (254) (Table 7). KNDM4 was the highest variety for TAC across locations. It did not performed well under unfavorable environment in Chiang Rai but it was still better than others (Table 6). However, anthocyanins of KNDM4 was rather fluctuated across environments as it has high $\mathrm{Sd}^{2}$. KNDM4 was suitable for favorable environments. KGW2 had the second rank for TAC (536 mg/100g DW), regression coefficient close to one (1.1) and low deviation from regression (67). This genotype was most stable for TAC across environments.

Table 7. Stability parameters for total anthocyanin content (TAC), cyanidin 3-glucoside (C3G), pelargonidin 3-glucoside (Pg3G), and peonidin 3-glucoside (Pn3G) of six waxy corn lines/cultivars.

\begin{tabular}{|c|c|c|c|c|c|c|c|c|c|c|c|c|}
\hline \multirow[t]{2}{*}{ Genotypes } & \multicolumn{3}{|c|}{$\begin{array}{l}\text { TAC } \\
(\mathrm{mg} / 100 \mathrm{gDW})\end{array}$} & \multicolumn{3}{|c|}{$\begin{array}{l}\text { C3G } \\
(\mathrm{mg} / 100 \mathrm{gDW})\end{array}$} & \multicolumn{3}{|c|}{$\begin{array}{l}\text { Pg3G } \\
(\mathrm{mg} / 100 \text { gDW) }\end{array}$} & \multicolumn{3}{|c|}{$\begin{array}{l}\text { Pn3G } \\
(\mathrm{mg} / 100 \text { gDW) }\end{array}$} \\
\hline & Mean & $b^{1 /}$ & $\mathbf{S d}^{2}$ & Mean & b & $\mathbf{S d}^{2}$ & Mean & b & $\mathbf{S d}^{2}$ & Mean & b & $\mathbf{S d}^{2}$ \\
\hline \multicolumn{13}{|c|}{ Purple waxy corn } \\
\hline KGW1 & $263^{\mathrm{e}}$ & 0.9 & 34 & $12^{\mathrm{e}}$ & $0.3^{* *}$ & 2 & $4^{\mathrm{e}}$ & $0.2 * *$ & 1 & $3.5 \mathrm{~d}$ & $0.1 * *$ & 0.4 \\
\hline KGW2 & $536^{\mathrm{b}}$ & 1.1 & 67 & $71^{\mathrm{b}}$ & 1.8 & 14 & $18^{\mathrm{c}}$ & 1.2 & 2 & $15.1 \mathrm{~b}$ & $1.4 * *$ & 0.3 \\
\hline KGW3 & $367^{\mathrm{d}}$ & 0.5 & 45 & $30^{\mathrm{c}}$ & 0.7 & 4 & $11^{\mathrm{d}}$ & $0.6^{* * *}$ & 1 & $10.9 \mathrm{c}$ & 1.0 & 1.7 \\
\hline KNDM4 & $903^{\mathrm{a}}$ & 0.9 & 254 & $93^{\mathrm{a}}$ & 1.7 & 24 & $35^{\mathrm{a}}$ & $1.7 * *$ & 3 & $19.2 \mathrm{a}$ & 1.3 & 5.4 \\
\hline FANCY111 & $468^{\mathrm{c}}$ & 1.6 & 120 & $21^{\mathrm{d}}$ & 0.5 & 4 & $22^{\mathrm{b}}$ & $1.4 * *$ & 1 & $10.4 \mathrm{c}$ & 1.1 & 1.9 \\
\hline
\end{tabular}

White waxy corn

$\begin{array}{llll}\text { FANCY121 } & 4 & 1 & 2\end{array}$

** Significant different from 1 at $P \leq 0.01$

Means in the same column with the same letter(s) were not significantly different at $P \leq 0.05$ probability level by LSD.

${ }^{1 /}$ Regression coefficients were analyzed without white waxy corn.

KNDM4 had the highest C3G (93 mg /100 gDW) followed by KGW2 (71 mg /100 gDW) and their regression coefficients were not different from one (1.7 and 1.8, respectively). However, their deviations from regression were high, indicating that they performed well under favorable conditions but performed poorly under unfavorable conditions (Chiang Rai). KGW1 had the lowest C3G (12 mg/100 gDW) and regression coefficient $\left(0.3^{* *}\right)$ was significantly lower than one, indicating that this genotype had low $\mathrm{C} 3 \mathrm{G}$ and stability for $\mathrm{C} 3 \mathrm{G}$ across environments.

Regression coefficients for $\mathrm{Pg} 3 \mathrm{G}$ for most genotypes were significantly different from one except KGW2, indicating that these genotypes were not stable for this trait. KNDM4 had the highest Pg3G of $35 \mathrm{mg} / 100 \mathrm{~g}$ DW followed by FANCY111 (22 mg/100g DW) but regression coefficients $\left(1.7^{* *}\right.$ and $1.4 * *$, respectively) were significantly higher than one, indicating that these genotypes performed well under favorable conditions but they had low Pg3G under unfavorable conditions.
KNDM4 had the highest Pn3G (19.2 mg/100 gDW), regression coefficient close to one (1.3) and high deviation from regression. However, it performed best for all locations but it had low Pn3G under unfavorable conditions (Chiang Rai) (Table 5). KGW2 showed high Pn3G (15.1 mg/100 gDW) but it had regression coefficient higher than one $\left(1.4^{* *}\right)$ and low deviation from regression, indicating that it performed well for Pn3G under favorable conditions but performed poorly under unfavorable conditions.

KNDM4 had the highest DPPH $(18.0 \mu \mathrm{mol} / \mathrm{gDW})$, regression coefficient smaller than one $(0.3 * *)$ and high deviation from regression (13.6) (Table 8). This genotype showed good adaptation to favorable conditions but it had poor adaptation to unfavorable conditions. KGW3 and KGW2 had high TEAC and regression coefficient close to one with high deviation from regression. Therefore, they may be suitable for some specific conditions. 
Table 8. Stability parameters for DPPH radical scavenging activity of phenolics (DPPH) and the Trolox equivalent anti-oxidant potential (TEAC) of six waxy corn lines/cultivars.

\begin{tabular}{|c|c|c|c|c|c|c|}
\hline \multirow[t]{2}{*}{ Genotypes } & \multicolumn{3}{|c|}{$\begin{array}{c}\text { DPPH } \\
(\mu \mathrm{mol} / \mathrm{gDW})\end{array}$} & \multicolumn{3}{|c|}{$\begin{array}{c}\text { TEAC } \\
(\mu \mathrm{mol} / \mathrm{gDW})\end{array}$} \\
\hline & Mean & $\mathbf{b}$ & $\mathbf{S d}^{2}$ & Mean & $\mathbf{b}$ & $\mathbf{S d}^{2}$ \\
\hline \multicolumn{7}{|l|}{ Purple waxy corn } \\
\hline KGW1 & $11.8^{\mathrm{d}}$ & 1.0 & 3.0 & $2.6^{\mathrm{d}}$ & 0.8 & 0.9 \\
\hline KGW2 & $14.6^{\mathrm{c}}$ & 1.1 & 0.3 & $4.9^{\mathrm{ab}}$ & 1.0 & 2.0 \\
\hline KGW3 & $14.3^{\mathrm{c}}$ & $1.3 * *$ & 0.3 & $5.0^{\mathrm{a}}$ & 0.6 & 2.4 \\
\hline KNDM4 & $18.0^{\mathrm{a}}$ & $0.3 * *$ & 13.6 & $4.8^{\mathrm{b}}$ & 0.9 & 2.5 \\
\hline FANCY111 & $15.9^{\mathrm{b}}$ & 1.3 & 1.3 & $4.1^{\mathrm{c}}$ & $1.6 * *$ & 1.5 \\
\hline \multicolumn{7}{|l|}{ White waxy corn } \\
\hline FANCY121 & 5.2 & & & 0.2 & & \\
\hline
\end{tabular}

Khampas et al. (2013) and Harakotr et al. (2014) reported that kernels of purple waxy corn had high TAC and antioxidant activity (DPPH, FRAP and TEAC). In this study, cobs of purple waxy corn also had high TAC and antioxidant activity, and cobs can be used for production of natural colorant with health benefits.

\section{CONCLUSION}

Location (L), genotype (G) and GxL interaction were highly significant for all characters. Location contributed to large portion of total variation in anthocyanin content and antioxidant activity in corn cobs, whereas genotype and genotype by location interaction contributed smaller portions of total variations in these traits. Nakhon Ratchasima, which was characterized by low temperature and low phosphorus, was the highest location for TAC and $\mathrm{C} 3 \mathrm{G}$. KNDM4 gave the highest TAC and $\mathrm{C} 3 \mathrm{G}$, and its regression coefficients (b) were close to one. However, KNDM4 also had the highest $\mathrm{Sd}^{2}$, indicating that it had specific adaptation to favorable environments. KNDM4 performed well under unfavorable environments for all traits. This information is useful for breeding programs in multi-location trails and production of anthocyanins from purple waxy corn.

\section{ACKNOWLEDGEMENTS}

The project was funded by the Thailand Research Fund, the commission for High Education and Khon Kaen University through the Distinguished Research Professor Grant of Professor Dr. Aran Patanothai and the Plant Breeding Research Center for Sustainable Agriculture, Faculty of Agriculture, Khon Kaen University, Thailand. Acknowledgement is extended to Khon Kaen University and the Faculty of Agriculture for providing financial support for manuscript preparation activities.

\section{LITERATURE CITED}

Altay, F. 2012. Yield stability of some Turkish winter wheat (Triticum aestivum L.) genotypes in the western transitional zone of Turkey. Turk. J. Field Crops 17:129-134.

Bordignon-Luiz, M.T., C. Gauche, E.F. Gris and L.D. Falcao. 2007. Colour stability of anthocyanins from Isabel grapes (Vitis labrusca L.) in model systems. LWT-Food Sci. Technol. 40:594-599.
Cevallos-Casals, B.A. and L. Cisneros-Zevallos. 2003. Stoichiometric and kinetic studies of phenolic antioxidants from Andean purple corn and red-fleshed sweet potato. J. Agric. Food Chem. 51:3313-3319.

Cevallos-Casals, B.A. and L. Cisneros-Zevallos. 2004. Stability of anthocyanin-based aqueous extracts of Andean purple corn and redfleshed sweet potato compared to synthetic and natural colorants. Food Chem. 86:69-77.

Chalker-Scott, L. 1999. Environmental significance of anthocyanins in plant stress responses. J. Photochem. Photobiol. 70:1-9.

Chander, S., Y. Meng, Y. Zhang, J. Yan and J. Li. 2008. Comparison of nutritional traits variability in selected eighty-seven inbreds from Chinese maize (Zea mays L.) germplasm. J. Agric. Food Chem. 56:6506-6511.

Christie, P.J., M.R. Alfenito and V. Walbot. 1994. Impact of low-temperature stress on general phenylpropanoid and anthocyanin pathways: enhancement of transcript abundance and anthocyanin pigmentation in maize seedlings. Planta. 194:541-549.

Cobbina J. and M.H. Miller. 1987. Purpling in maize hybrids as influenced by temperature and soil phosphorus. Agron. J. 79:576-582.

de Pascual-Teresa S. and M.T. Sanchez-Ballesta. 2008. Anthocyanins: from plant to health. Phytochem. Rev. 7(12):281-299.

de Rosso, V.V. and A.Z. Mercadante. 2007. Evaluation of colour and stability of anthocyanins from tropical fruits in an isotonic soft drink system. Innovative Food Sci. Emerging Technol. 8:347-352.

Eberhart, S.A. and W.A. Russel. 1966. Stability parameters for controlling variation. Crop Sci. 6:36-40.

Fournier-Level, A., L. Le Cunff, C. Gomez, A. Doligez, A. Ageorges, C. Roux, Y. Bertrand, J.M. Souquet, V. Cheynier and P. This. 2009. Quantitative genetic bases of anthocyanin variation in grape (Vitis vinifera $\mathrm{L}$. ssp. sativa) Berry: A Quantitative trait locus to quantitative trait nucleotide integrated study. Genetics 183:1127-1139.

Giusti, M.M. and R.E. Wrolstad. 2001. Characterization and measurement of anthocyanins by UV-visible spectroscopy. In: Current Protocol in Food Analytical Chemistry, ed. Wrolstad, R.E., 5:1-13, John Willy \& Sons Inc., New York.

Harakotr, B., B. Suriharn, R. Tangwongchai, M.P. Scott and K. Lertrat. 2014. Anthocyanins and antioxidant activity in coloured waxy corn at different maturation stages. J. Funct. Foods 9:109-118.

Hodges D.M. and C. Nozzolillo. 1996. Anthocyanin and anthocyanoplast content of cruciferous seedlings subjected to mineral nutrient deficiencies. J. Plant Physiol. 147:749-754. 
Hussanun, S., B. Suriharn, K. Lertrat. 2014. Yield and early maturity response to four cycles of modified mass selection in purple waxy corn. Turk. J. Field Crops 19:84-89.

Janda, T., G. Szalai and E. Paldi. 1996. Chlorophyll fluorescence and anthocyanin content in chilled maize plants after return to a non-chilling temperature under various irradiances. Biol. Plant. 38:625-627.

Jemai, H., M. Bouaziz and S. Sayadi. 2009. Phenolic composition, sugar contents and antioxidant activity of Tunisian sweet olive cultivar with regard to fruit ripening. J. Agric. Food Chem. 57:2961-2968.

Jing, P., V. Noriega, S.J. Schwartz and M.M. Giusti. 2007. Effects of growing conditions on purple corncob (Zea mays L.) anthocyanins. J. Agric. Food Chem. 55:8625-8629.

Khampas, S., K. Lertrat, K. Lomthaisong, and B. Suriharn. 2013. Variability in phytochemicals and antioxidant activity in corn at immaturity and physiological maturity stages. Inter. Food Res. J. 20:3149-3157.

Kim, M.J., J.N. Hyun, J.A. Kim, J.C. Park, M.Y. Kim, J.G. Kim, S.J. Lee, S.C. Chun and I.M. Chung. 2007. Relationship between phenolic compounds, anthocyanins content and antioxidant activity in colored barley germplasm. J. Agric. Food Chem. 55:4802-4809.

Knievel, D.C., E.S.M. Abdel-Aal, I. Rabalski, T. Nakamura and T. Hucl. 2009. Grain color development and the inheritance of high anthocyanin blue aleurone and purple pericarp in spring wheat (Triticum aestivum L.). J. Cereal Sci. 50:113120.

Lachman, J., K. Hamouz, M. Orsák, V. Pivec and P. Dvořák. 2008. The influence of flesh colour and growing locality on polyphenolic content and antioxidant activity in potatoes. Sci. Hortic. 117:109-114.

Leng, P., H. Itamura, H. Yamamura and X.M. Deng. 2000. Anthocyanin accumulation in apple and peach shoots during cold acclimation. Sci. Hortic. 83:43-50.

Li, C.Y., H.W. Kim, S.R. Won, H.K. Min, K.J. Park, J.Y. Park, M.S. Ahn and H.I. Rhee. 2008. Corn husk as a potential source of anthocyanins. J. Agric. Food Chem. 56:1141311416.

Mitrović, B., D. Stanisavljevi, S. Treski, M. Stojaković, M. Ivanović, G. Bekavac and M. Rajković. 2012. Evaluation of Experimental Maize Hybrids Tested in Multi-Location Trials Using AMMI and GGE Biplot Analyses. Turk. J. Field Crops 17:35-40.

Mohammadi, M., R. Karimizadeh, N. Sabaghnia and M.K. Shefazadeh. 2012. Genotype x environment interaction and yield stability analysis of new improved bread wheat genotypes. Turk. J. Field Crops 17:67-73.

Mollov, P., K. Mihalev, V. Shikov, N. Yoncheva and V. Karagyozov. 2007. Colour stability improvement of strawberry beverage by fortification with polyphenolic copigments naturally occurring in rose petals. Innovative Food Sci. Emerging Technol. 8:318-321.

Moreno, Y.S., G.S. Sánchez, D.R. Hernández, N.R. Lobato. 2005. Characterization of anthocyanin extracts from maize kernels. J. Chromatogr. Sci., 43:483-487.

Oren-Shamir, M. and A. Levi-Nissim 1997. UV-light effect on the leaf pigmentation of Cotinus coggygria 'Royal Purple'. Sci. Hort. 71:59-66.

Reyes, L.E., J.C. Miller, and L. Cisneros-Zevallos. 2004. Environmental conditions influence the content and yield of anthocyanins and total phenolics in purple- and red-flesh potatoes during tuber development. Amer. J. of Potato Res. 81:187-193.

Thiraphatthanavong, P., J. Wattanathorn, S. Muchimapura, W. Thukham-mee, P. Wannanon, T. Tong-un, B. Suriharn, and K. Lertrat. 2014. Preventive Effect of Zea mays L. (Purple Waxy Corn) on Experimental Diabetic Cataract. Biomed. Res. Int., 1-8.

Veigas, J.M., M.S. Narayan, P.M. Laxman and B. Neelwarne. 2007. Chemical nature, stability and bioefficacies of anthocyanins from fruit peel of syzygium cumini Skeels. Food Chem. 105:619-627.

Vizzotto, M., L. Cisneros-Zevallos and D.H. Byrne. 2007. Large variation found in the phytochemical and antioxidant activity of peach and plum germplasm. J. Amer. Soc. Hort. Sci. 132(3):334-340

Wang, L. and G.D. Stoner. 2008. Anthocyanins and their role in cancer prevention. Cancer Lett. 269:281-290.

Wang, S.Y. and W. Zheng. 2001. Effects of plant growth temperature on antioxidant capacity in strawberry. J. Agric. Food Chem. 49:4977-4982.

Xu, J.G., Q.P. Hu, X.D. Wang, J.Y. Luo, Y. Liu and C.R. Tian. 2010. Changes in the main nutrients, phytochemicals, and antioxidant activity in yellow corn grain during maturation. J. Agric. Food Chem. 58:5751-5756.

Yang, Z., G. Fan, Z. Gu, Y. Han and Z. Chen. 2008. Optimization extraction of anthocyanins from purple corn (Zea mays L.) cob using tristimulus colorimetry. Eur. J. Lipid Sci. Tech. 227:409-415.

Yang, Z. and W. Zhai. 2010. Identification and antioxidant activity of anthocyanins extracted from the seed and cob of purple corn (Zea mays L.). Innovative Food Sci. Emerging Technol. 11:169-176.

Zhao, X., M. Corrales, C. Zhang, X. Hu, Y. Ma and B. Tauscher. 2008. Composition and thermal stability of anthocyanins from chinese purple corn (Zea mays L.). J Agric Food Chem. 56:10761-10766. 